\title{
RESISTING PESSIMISM TRAPS: THE LIMITS OF BELIEVING IN ONESELF ${ }^{1}$
}

\author{
Jennifer M. Morton \\ University of North Carolina-Chapel Hill \\ (Forthcoming in Philosophy and Phenomenological Research)
}

\begin{abstract}
Members of marginalized groups who desire to pursue ambitious ends that might lead them to overcome disadvantage often face evidential situations that do not support the belief that they will succeed. Such agents might decide, reasonably, that their efforts are better expended elsewhere. If an agent has a less risky, valuable alternative, then quitting can be a rational way of avoiding the potential costs of failure. However, in reaching this pessimistic conclusion, she adds to the evidence that formed the basis for her pessimism in the first place, not just for herself but for future agents who will be in a similar position as hers. This is a pessimism trap. Might believing optimistically against the evidence offer a way out? In this paper, I argue against practical and moral arguments to turn to optimism as a solution to pessimism traps. I suggest that these theories ignore the opportunity costs that agents pay when they settle on difficult long-term ends without being sensitive to evidence of potential failure. The view I defend licenses optimism in a narrow range of cases. Its limitations show us that the right response to many pessimism traps is not to be found through individual optimism.
\end{abstract}

Optimism plays an important role in the successful pursuit of difficult, long-term projects. When we encounter setbacks and rejection, it is tempting to start doubting whether our efforts will be for naught. And if pessimism gets the best of us, we might simply quit. But if we are too quick to give up whenever we encounter a challenge, we are unlikely to accomplish many of the difficult goals we set for ourselves. Those who succeed seem to do so because they persist and their ability to believe in themselves appears to be an important part of how they persist.

But can believing in oneself help members of marginalized groups overcome the sort of challenge that poverty, prejudice, and discrimination pose? Some suggest that it can. Not only do we encounter the advice to 'believe in yourself' in the self-help aisles, but, as we will see in section I, economists and psychologists are increasingly interested in touting the power of confidence and hope. Esther Duflo (2012), recent winner of the Nobel Prize in economics, writes that "Hope can fuel aspiration" (p. 40) and play an important role in enabling those in poverty to pursue more ambitious goals. Likewise, the psychological literature on the pernicious effects of prejudice and discrimination seems to suggest that agents' lack of faith in their own capacities is an impediment to success (Britner and Pajares 2001). And

\footnotetext{
${ }^{1}$ For their insightful feedback, I must thank Michael Bratman, Luc Bovens, Tom Dougherty, Ryan Muldoon, Daniel Singer, Sarah Paul, Catherine Rioux, Kate Ritchie, Vanessa Wills, and Manuel Vargas. This paper also greatly benefitted from lively discussions with audiences at Stanford University, the Centre de Recherche en Éthique at the University of Montreal, the University of Warwick, the University of Reading, the University of Pennsylvania's Philosophy of Race Conference, the Wharton Work in Progress Series, The Ohio State University, Brandeis University, Duke University, Georgia State, the University of North Carolina at Chapel Hill, and Cal State-San Bernardino. Finally, I am indebted to the referees for this journal.
} 
research by Elizabeth Tenny and her collaborators (2015) shows that lay people also subscribe to the hypothesis that optimism can improve one's likelihood of success.

The worry is that agents in adverse conditions are subject to what I will describe in section II as pessimism traps. An agent is stuck in a pessimism trap when her lack of confidence that she will succeed in the pursuit of an ambitious end $\mathrm{E}_{\mathrm{A}}$ leads her to pursue a less risky alternative $\mathrm{E}_{\mathrm{M}}$, but in so doing she reinforces the evidential basis that led to her pessimistic assessment in the first place, not just for herself but for others who are similarly positioned. The student in a high-poverty school who decides not to pursue college because the evidence available to her supports the belief that people in her circumstances are unlikely to succeed in that pursuit is falling into a pessimism trap. By not successfully pursuing this course of action, she is not only failing to provide countervailing evidence that people like her can succeed in that pursuit but she has reinforced the evidential basis for the next student who will reach a similarly pessimistic conclusion. The question we will consider in this paper is whether there are good pragmatic or moral arguments that can motivate the thought that this student can escape this pessimism trap by cultivating optimism despite the evidence.

In section III, I will argue against the view that agents in conditions of adversity have pragmatic reasons to cultivate optimism. I consider several pragmatic encroachment theories that would seem to license an agent's belief that they will succeed in pursuing an ambitious end $\mathrm{E}_{\mathrm{A}}$ despite the evidence. I suggest that these theories ignore the very real opportunity costs that agents pay when they settle on difficult long-term ends without being sensitive to evidence of potential failure. The appeal to optimism as a tool in combatting challenging economic and social circumstances relies on a failure to appreciate the dangers of believing against the evidence, in particular, for agents in vulnerable positions. In section IV, I will argue against the view that such agents have moral reasons to believe against the evidence. Agents who are already in vulnerable positions do not have a moral obligation to take on additional potentially costly risks in order to provide evidence for future agents in similar positions. Though such trailblazers are admirable, to put the responsibility for changing the evidential conditions faced by those in conditions of adversity on vulnerable agents reinforces the oppressive harms that such agents already face.

Relying on a theory of epistemic resilience modeled as an epistemic policy that I have defended elsewhere with Sarah Paul (2019), I argue in section V that it is rational for an agent to believe optimistically but only in a very narrow range of cases - only when two impartial spectators looking at the evidence could reasonably disagree about what the evidence shows. Unfortunately, many agents who face adverse circumstances due to poverty, discrimination, or prejudice are in situations that fall outside that evidential range. The evidence in their case points to the pessimistic conclusion and they would do well to heed it. Nonetheless, this theory allows us to differentiate reasonable from unreasonable appeals to optimism. In doing so, it helps clarify the debate between those who think that the psychology of victims of oppression can play a role in overcoming (or exacerbating) the challenges they face and those who think that under oppressive material conditions it is unreasonable to expect that victims believe against the evidence. In section VI, I discuss the possibility of a collective response to pessimism traps. I conclude by reflecting on the importance of taking seriously the evidential conditions of rational agency when we are seeking to combat the challenges to which poverty, prejudice, and discrimination give rise. 


\section{The Appeal of Optimism}

Motivation is closely linked to whether we believe success in a pursuit is likely. In many cases, if we believe we will fail, we might as well not try. ${ }^{2}$ It stands to reason then that believing we will succeed would keep us motivated even when we encounter evidence that might deflate our confidence. This disposition to believe in our success even in the face of contrary evidence is how I will think of what gets called 'optimism' or 'hope' in some of the empirical literature. ${ }^{3}$ Psychologists, economists, and writers in the popular media have touted optimism as an important tool in combatting the obstacles and challenges that arise in the pursuit of difficult long-term goals, in particular, for those whose agency is threatened by poverty, racism, sexism, and other forms of adversity.

Psychologist Angela Duckworth (2016), whose work on grit has been extremely influential, emphasizes the importance of optimism in fostering the capacity to persevere in the face of challenges and setbacks. ${ }^{4}$ Building on work by the father of positive psychology, Martin Seligman (2006), she suggests that we should intentionally cultivate hope and optimism as a way to overcome difficult challenges. ${ }^{5}$ A similar line of thought can be found in Abhijit Banerjee and Esther Duflo's (2011) work. The economists, who won the 2019 Nobel Prize (along with Michael Kremer) for their pioneering work using randomized control trails to evaluate the effectiveness of different interventions aimed at disrupting poverty traps, tout hope and optimism as an important overlooked factor in combatting poverty. They show, for example, that a micro-credit program that targets those in extreme poverty with assets and longterm support has sizeable positive effects on the treatment group's food security, consumption, income, and other measures that are critical to wellbeing. These sizeable effects cannot be accounted for solely by the initial financial boost. Though Duflo (2012) admits that we don't fully understand the mechanisms at play, she argues that one plausible factor at play is that the intervention gives participants "hope and the sense that they had been given a chance" and that this is "what motivated them to succeed" (p. 31). She writes that, "the existence of a step that is too high to climb creates a rational temptation to hold back, to avoid trying too hard. Having not tried, individuals may never discover what they are capable of. This worsens the poverty trap, or in some cases creates one where there was not one in the first place" (p.41). The thought is that pessimism about one's prospects can be self-fulfilling and further entrench poverty; optimism, in contrast, can fuel the aspiration that propels those trapped in poverty to pursue more ambitious goals that might materially change their life circumstances.

A similar mechanism might be at play in stereotype threat. Claude Steele and Joshua Aronson's (1995) pioneering work on stereotype threat shows that in situations in which members of stereotyped groups are reminded of pervasive negative stereotypes tied to their group identity, they underperform in ways that confirm the stereotypes (e.g. women and minorities attaining lower scores in math tests). Again,

\footnotetext{
${ }^{2}$ In cases in which not trying is worse (e.g. we are holding on to a cliff's ledge), then certainly we should try even if we think that we will fail. However, in most standard cases agents have less risky alternatives. Another possibility I do not consider here is whether agents can pursue a risky goal, while at the same time engaging in contingency planning. For a thoughtful discussion of this option see Sarah Paul (2021).

${ }^{3}$ We might attempt to model the attitude referenced by these social scientists in different ways. In this paper, I suggest it is a 'disposition to belief' because doing so better captures many of the roles that these social scientists expect the attitude to play in our practical reasoning. I discuss hope as an alternative in section IV.

${ }^{4}$ Much of the psychological work in this area treats hope, optimism, and Carol Dweck's 'growth mindset' similarly. There is much more work that could be done philosophically to clarify the distinction between these three notions, but it would take us too far astray to do so here. For the purposes of this essay, I am focused on optimistic beliefs about one's likelihood of success.

${ }^{5}$ Bandura's (1977) research on the importance of 'self-efficacy' is an even earlier version of a similar idea.
} 
the mechanisms here are not well-understood, but Cohen et al. (2009) suggest that "in chronically evaluative settings such as school... A feedback loop, with psychological threat and poor performance reinforcing one another, can create worsening performance over time" (p. 402). That is, the worsening performance triggered by the threat of confirming the stereotype erodes the student's confidence and thus leads to a negative feedback loop. Cohen et al. $(2006,2009)$ found some success in mitigating these effects through interventions that encourage participants to affirm their personal values. Joshua Aronson et al. (2002) find that an intervention that promotes a growth mindset about intelligence- the view that intelligence is malleable and can be expanded through hard work - mitigates some of the achievement gap between Black and White students. The thought driving both of these interventions is that promoting positive beliefs can mitigate the negative feedback loop created by stereotype threat.

Much of the research that touts optimism as a critical factor in overcoming obstacles generated by poverty, racism, and sexism appears to be motivated by the thought that pessimistic beliefs are selffulfilling, and that optimism is the natural remedy. Psychologists Elizabeth Tenney and her collaborators (2015) find that ordinary people also subscribe to what they call the optimism-performance hypothesis: "they believe that having an optimistic outlook will improve performance when working toward a goal, which then increases the chance of success" (p. 377). If pessimism is one factor that holds agents in conditions of adversity back, then it seems natural to suggest that cultivating positive beliefs about one's likelihood of success is a critical tool in overcoming the challenges in one's path.

\section{Pessimism Traps}

Agents who face adversity due to their socioeconomic background, race, or gender are liable to get caught in pessimism traps - failing to pursue an ambitious end $\mathrm{E}_{\mathrm{A}}$ on the basis of evidence that agents in their circumstances are unlikely to succeed and thereby reinforcing the evidential basis that leads to the pessimistic assessment in the first place. The idea of a pessimism trap, as developed in this paper, is meant to capture how negative beliefs about one's likelihood of success can play a role in agents pursuing less risky, modest ends instead of ambitious ones, thereby further entrenching the negative evidence that the agent herself and other agents in a similar position face. The central idea, however, has broader applicability. For example, the agent who is trying to get back in shape but quits his exercise regime because he succumbs to the thought that he doesn't have the self-discipline to follow through is, arguably, falling prey to a pessimism trap. In quitting, he is providing himself with further evidence that he does not have what it takes and, thus, confirming his negative self-assessment. Though the broader set of cases is interesting in its own right, for the purposes of this paper, I will focus on those cases in which poverty, prejudice, and discrimination play a role in providing agents with the sort of evidence that would prima facie make it rational for them to arrive at the pessimistic beliefs that play a role in thwarting their ambition.

To sharpen our discussion, I will focus on a set of cases in which agents resist pursuing long-term, difficult ends because they have sufficient evidence that poverty, prejudice, or discrimination are likely to imperil their path and there is a less risky but valuable alternative available.

JULIO is growing up in a mining town in the Andes. His family is poor; they struggle to put food on the table, to pay for medical care, and to send their children to school. He walks an hour to school each day, but his grades in school have been stellar. A teacher suggests he might consider making the trip to the capital, Lima, to enroll in university and become an engineer. Julio does not 
know anybody who has pursued this path successfully, though he knows he is academically talented. His dad could use an extra pair of hands selling produce at the market. He thinks he could help his dad grow the business and maybe eventually start his own.

MALCOLM, a young African American man growing up in the United States in the 1930s, is asked by his teacher what he wants to be when he grows up. He thinks he wants to be a lawyer. However, there are no African American lawyers in his town. He has not met anyone Black who has succeeded at becoming a lawyer. And he knows that prejudice and discrimination are rampant and the path to becoming a lawyer would be difficult. His teacher points out that Malcolm is good with his hands and that a more 'realistic' career path is carpentry. Malcolm does like carpentry and thinks that if he pursued it, he could make a decent living for a Black man in his town. ${ }^{6}$

CLARA, a Latina philosophy undergraduate, is interested in pursuing an academic career. Her philosophy classes are disproportionately male and white. In class, Clara reads various philosophers, including Plato, Aristotle, Locke, Hobbes, none of whom are female and all of whom are white. Her professors have all been white men. Clara has also been doing well in her sociology classes. She has had Latinx professors and has read many non-White authors in those courses. Even though Clara finds philosophy very engaging and gets good grades, given the evidence at her disposal, it seems to her that philosophy is not for people like her.

Let me briefly highlight a few important features of these cases.

- They involve difficult, long-term ends that require agents to overcome obstacles and challenges in their pursuit. Pursuing these ends - going to university, becoming a lawyer, or pursuing a career in philosophy - requires that one be committed to them over a long period of time during which one will encounter inevitable challenges or setbacks that will threaten one's confidence.

- The agents have feasible, valuable alternatives available to them. Another way of putting this point is that Julio, Malcolm, and Clara do not value pursuing the ambitious ends so much more than the less risky alternative they also value.

- The agents do not have an unusual appetite for risk or an unusual tolerance for risk (Buchak 2013). Julio, Malcolm, and Clara are not interested in pursuing risky options because they are risky or because they are insensitive to the risk involved. ${ }^{7}$

- They have very strong evidence that the likelihood of succeeding at end $\mathrm{E}_{\mathrm{A}}$ for someone from group $\mathrm{G}$ (a group in which they self-identify or have a reasonable expectation other people

\footnotetext{
${ }^{6}$ This case is loosely based on a story recounted in the Autobiography of Malcolm X (2015): “[Malcom's X's Teacher] told me, "Malcolm, you ought to be thinking about a career. Have you been giving it thought?" The truth is, I hadn't. I never have figured out why I told him, "Well, yes, sir, I've been thinking I'd like to be a lawyer." Lansing certainly had no $\mathrm{N}^{* * * *}$ lawyers -- or doctors either -- in those days, to hold up an image I might have aspired to. All I really knew for certain was that a lawyer didn't wash dishes, as I was doing. Mr. Ostrowski looked surprised, I remember, and leaned back in his chair and clasped his hands behind his head. He kind of half-smiled and said, "Malcolm, one of life's first needs is for us to be realistic. Don't misunderstand me, now. We all here like you, you know that. But you've got to be realistic about being a $\mathrm{n}^{* * * * *}$. A lawyer -- that's no realistic goal for a $\mathrm{n}^{* * * * *}$. You need to think about something you can be. You're good with your hands -- making things. Everybody admires your carpentry shop work. Why don't you plan on carpentry? People like you as a person -- you'd get all kinds of work." (p. 43)

${ }^{7}$ Thanks to Sarah Paul for urging me to clarify this point.
} 
identify them as belonging to) or from circumstances $\mathrm{C}$ is very low, and the likelihood of succeeding in the pursuit of the alternative is higher.

- If they fail to pursue end $\mathrm{E}_{\mathrm{A}}$, the evidence that supports the pessimistic assessment will remain unchanged or be slightly worse.

I focus on these cases for several reasons. The first is that the pursuit of difficult, long-term ends is important to many of us. These commitments often give our lives the shape they have. They constrain our practical reasoning and change how we evaluate our reasons going forward (Michael Bratman 1984, 200, 2004a, 2004b). Second, in embarking on many of these pursuits, we pay steep opportunity costs. A life devoted to building a business or attending graduate school excludes many other valuable ends we could have pursued. Finally, these pursuits are also ones in which we are likely to encounter setbacks and challenges that undermine our confidence, and when we do, we are liable to feel the pull of the unchosen alternative (Morton \& Paul 2019). Poverty, prejudice, and discrimination often lead to precisely the sort of challenges and setbacks that might undermine an agent's confidence.

In the discussion that follows, I will be considering whether there is a way for agents to resist falling prey to pessimism traps. I am taking for granted that in these cases the evidence does lend support to a pessimistic assessment of their likelihood of success. I will not be focused on agents who are pessimistic despite having evidence that they are likely to succeed. Such agents are epistemically irrational in a rather straightforward way. What is interesting about the cases in question is that there is a prima facie case to be made that these agents are behaving rationally in concluding that they are unlikely to succeed. ${ }^{8}$

Some might worry that using generalizations about people like them is already putting these agents on an epistemically precarious footing. I return to this point in the next section but note that most of us use such generalizations in deciding whether we are likely to succeed in the pursuit of novel ends. In assessing the very low likelihood that I would succeed as an WNBA star, I use generalizations about people with similar talent to mine who are short of stature. ${ }^{9}$ Of course, these generalizations must be taken into account along with the evidence one has about one's own particular circumstances, skills, and abilities. ${ }^{10}$ Clara has evidence that her papers are insightful and well-argued. Malcolm has evidence that he is one of the strongest students in his class. And Julio has evidence that his teacher thinks he could succeed at pursuing a university education. However, this is not evidence that would defeat their pessimistic assessment that agents like themselves are unlikely to succeed in the pursuit of $\mathrm{E}_{\mathrm{A} .}{ }^{11}$ Many smart, hard-working poor, Black, and Latinx people do not become lawyers, professors, or obtain college degrees. $^{12}$

\footnotetext{
${ }^{8}$ I do not take a position on how exactly agents arrive at these beliefs. I am not assuming that they are perfect Bayesian updaters. Agents might use heuristics - for example, by relying on paradigms or, even, broad generalizations that are prevalent in their community - to determine whether members of their relevant group do in fact succeed in the pursuit of ambitious end $\mathrm{E}_{\mathrm{A}}$. Thanks to Tom Dougherty for urging me to clarify this point.

${ }^{9}$ For a discussion see Lippert-Rasmussen (2011). Thanks to Tom Dougherty for pressing me on this point.

${ }^{10}$ I turn to some cases in which the evidence suggests that the agent in question is really 'extraordinary' in the final section.

${ }^{11}$ Here is where Malcolm and Clara differ to some extent. Whereas for Malcolm the evidence clearly supports a belief that his race will negatively affect his prospects, Clara takes the evidence at her disposal to support a more inchoate sense that philosophy is "not for her." I return to this difference later.

${ }^{12}$ These agents might not accurately understand the mechanisms at play - they might have little knowledge of structural inequality or stereotype threats - but their sense that people from their group are less likely to succeed in
} 
The problem is that if these agents are right that they are unlikely to succeed, given that they have valuable less risky alternatives, many standard theories of rational choice would recommend pursuing the less risky, but also less ambitious end. Consider a range of actions $a_{1}, \ldots \ldots, a_{n}$ available to an agent. Within that range there will be actions whose outcomes would be valuable for the agent, but which are unlikely (e.g. winning the lottery). There are also actions whose outcomes are much more likely, but whose value to the agent is very low (e.g. counting blades of grass). Standard rational choice theory (RCT) would have the agent calculate the expected utility of each action based on the value of the possible outcomes including the opportunity costs associated with each and their corresponding likelihood. She would then maximize by settling on that option that will bring about the highest utility for her. ${ }^{13}$ Of course, everything depends on the relative value and likelihoods at stake in each particular case. However, when the options are both valuable to the agent and one entails a substantial risk, as they do in the cases in question, RCT will recommend the more modest end, in particular, when one option involves significant opportunity costs.

The problem is that RCT leaves little room for optimism to play a role. But as we saw in the previous section, there is a case to be made for an agent's optimistic beliefs enabling her to take on ambitious goals. ${ }^{14}$ The beliefs we have matter not just because they enable us to track the truth, but because they can play a role in changing what will be true of us. Pessimism traps prevent us from making the kind of ambitious decisions that would lead our agency in new directions. This point need not be denied by the proponent of RCT. But to take it on board requires that we think more carefully about how to approach such beliefs. In what follows, we will consider two ways to justify optimism as a response to pessimism traps-practical and moral.

\section{The Pragmatic Argument for Optimism}

If we accept various versions of evidentialism - the theory that in forming beliefs about $p$ one should only be responsive to the evidence concerning the truth of $p$ - then Julio, Malcolm, and Clara would seem to be licensed in forming the pessimist belief given the evidence at their disposal. ${ }^{15}$ However, if we can somehow block this move by arguing that considerations other than evidence are relevant to whether these agents should form pessimistic beliefs about their own probability of success, then we might be able to resist pessimism traps. It is widely agreed in the literature that forming beliefs directly on the basis of

the pursuit of the ambitious end in question is well-supported by the evidence. This is true of most agents in ordinary cases of choice. Many of us do not fully understand the mechanisms that preclude us from flying like a bird or running 3-minute miles, but we have roughly accurate assessments that we are unlikely to succeed at pursuing those ends. However, in some cases the agent might have evidence about the mechanisms underlying the statistical generalization that serve to undercut the generalization's applicability to their particular case. For example, an agent might learn that nobody from their relevant group $\mathrm{G}$ has succeed at end $\mathrm{E}$ because no Gs have wanted to pursue end E. In that case, the lack of Gs would not be good evidence that the agent in question would encounter significant challenges in the pursuit of E. I assume that this is not what is happening in the cases we are considering.

${ }^{13}$ I am setting aside considerations of the agent's risk profile (Buchak, 2013) here but return to them in the following section.

${ }^{14}$ Writing about hope, Luc Bovens (1999) argues that it can play a role in helping us realize our ends_-it has instrumental value.

${ }^{15}$ My discussion proceeds on the assumption that agents are forming beliefs about the relative likelihood of success in the agent's pursuit of an end compared to the relevant alternatives. Some might argue that the most natural way to model these attitudes is to use credences. When talking about practical reasoning, I think the phenomenology is better captured by talk of beliefs, but nothing I say here hinges on the rejection of credences as playing the role that I assign to beliefs. 
pragmatic reasons is psychologically difficult and normatively problematic. Some have argued that doing so is in tension with constitutive normative features of belief (Hieronymi 2009, Setiya 2008, Winters 1979). The most promising forms of pragmatic encroachment seem to be indirect. ${ }^{16}$ In what follows, I assume that the best way to make sense of the optimism at stake in these cases is not by licensing agents to reason on the basis of practical or moral reasons for believing directly, but rather by licensing them to deliberate in such a way that leads them to arrive at the sort of optimistic beliefs that enable their ambitions.

\section{Bad Faith Reasoning}

The first argument one might offer, inspired by Beri Marušić (2015), is that an agent reasoning about her own agency should not engage in the kind of theoretical reasoning that would require her to respond to evidence of how likely she is to succeed on pain of engaging in Sartrean bad faith. Marušić rejects evidentialism when it comes to practical beliefs about what one will do. He suggests that an agent deciding what to do should engage in practical reasoning which means considering the practical reasons that recommend the end. Predicting how likely one is to succeed on the basis of evidence is theoretical reasoning and not something that an agent ought to do on pain of treating herself as an object whose future is to be predicted and thus, in effect, denying her agency. Marušić writes: "when matters are up to us, we should not seek to predict what we will do, because in this way we would treat a matter that is up to us as if it were not up to us, and, in so doing, we would fail to take responsibility for our agency" (p. 124).

Marušić (2015) acknowledges that sometimes evidence that an end is challenging can make a difference to practical reasoning, but it does not do so by forming the basis of a prediction. Rather what evidence does is inform our understanding of how to approach the end. Julio, Malcolm, and Clara should take their evidence to show them that the pursuit of the end will require perseverance and that this might be stressful and exhausting (p. 129). However, this same evidence should not be treated as the basis of a prediction that they are unlikely to succeed. When making practical decisions, agents should consider the practical reasons that speak in favor of the end.

There are two problems for this view. The first is that it ignores opportunity costs. As I have argued with Sarah Paul (2019), the pursuit of difficult, long-term ends doesn't only require that we persevere in the face of challenges that we face, but that we are able to maintain our confidence in our choice when we can see that there are other valuable alternatives available. If Julio decides not to pursue higher education because he thinks that someone from his circumstances is unlikely to succeed at doing so, he need not be denying his own agency. He might be thinking that he could more effectively use his agency in the pursuit of other ends that are more likely to yield value. Considering evidence of difficulty in deciding whether an end is worthy of pursuit can be a way of taking responsibility not only for what we do, but for what we might have done instead. Engaging in this kind of comparative assessment of risk and difficulty is not necessarily in tension with taking our agency seriously.

Marušić might argue, plausibly, that the cases we have been discussing are ones in which success is not up to us and so not ones his theory is meant to address. But this leads us to the second problem for the view. He argues, for example, that calculating expected utility is rational when considering whether to buy a lottery ticket because the outcome of the lottery is not up to us. But, in general, Marušić suggests

\footnotetext{
${ }^{16}$ For skepticism of the distinction between direct and indirect forms of encroachment see Alex Worsnip (2020).
} 
we should not treat our future actions like the outcome of a lottery (p. 128). The problem is that there are many domains of agency, including the cases under discussion, in which we are less than certain of the outcomes of our actions because they depend on external factors that are largely out of our control. According to Marušić, we should either think of such cases as gambles, largely out of our control, or treat the end as if it were up to us by relying on the world's cooperation (p.170). But either of these analyses would misdescribe the cases in question. On the first analysis, many areas of the agency of marginalized groups would be seen as mere gambles outside of the purview of agency proper. But this dismisses the exercise of rational agency involved in making such decisions. On the second analysis, these agents should take responsibility by safely ignoring the ways in which the world might fail them. But doing so is often disastrous for members of marginalized social groups whose success is so often held hostage to poverty, prejudice, and discrimination.

\section{Faith in Oneself}

Ryan Preston-Roedder (2018) suggests that faith can play an important role in allowing an agent to resist the doubts that she might entertain when confronted with challenging circumstances. Faith, on his view, has cognitive, volitional, and emotional elements that allow one to resist self-doubt, cynicism, and other forms of pessimism that one might be liable to in the face of prejudice and discrimination. PrestonRoedder discusses the case of a child of Mexican immigrants who upon encountering prejudice of his intellectual abilities from his teachers and classmates turns to faith in order to counteract the doubts to which those experiences give rise (p. 175). In such a case, having faith involves an agent having "a limited form of optimism about her own capacity to adopt and carry out worthwhile projects, even in the face of obstacles" (p. 179). Preston-Roedder doesn't deny evidentialism, rather, he suggests that one can sustain that optimism by interpreting the evidence positively, paying careful attention to evidence that would bolster his faith, and so on. ${ }^{17}$ According to this view, then, the way for Julio, Malcolm, and Clara to respond to the situations they are in is to have faith in themselves. This would allow them to resist the doubts that would lead them not to pursue their respective ends. Preston-Roedder suggests that an important benefit of faith in oneself is precisely that it helps dismantle this kind of self-doubt.

The problem is that in the cases we are considering, having faith in oneself can be an incredibly risky proposition that is potentially very costly to the agent's life. Preston-Roedder suggests that courage is an important part of faith and that such courage is characterized by the agent's willingness to accept the risk that faith requires. But when does the courage constitutive of faith veer into foolish risk-taking? PrestonRoedder acknowledges that sometimes self-doubt can arise from evidence that an end is too risky or not worth pursuing. He suggests that a virtuous agent would be "judicious in deciding which risks to take" and even if she were to carry out the risky project she would remain "sensitive to new evidence concerning how it progresses" (p. 181). But this is where the tension between faith and evidentialism reappears. Either the agent is being sensitive to evidence of how risky the end is and adjusting what projects she pursues in light of it, thus potentially losing her grip on the faith that allows her to overcome self-doubt, or she maintains her faith by selectively ignoring some of the evidence, thus being epistemically irrational in the service of her faith and risking costly failure. We need an account that helps us assess the difference between a faithful agent who is judiciously assessing the risks and opportunity costs of her choice and the one who is relying on faith to take on injudicious risks.

\footnotetext{
${ }^{17}$ In this Preston-Roedder follows Sarah's Stroud (2006) account of epistemic partiality in friendship.
} 
I do not wish to deny that there is a role for faith in practical reasoning. For example, it might be that in cases in which the end is so valuable that its pursuit is worth any risk, faith is the only reasonable way to sustain the optimism required even if it is epistemically irrational. But these are different cases than the ones we are considering here. The concern in the cases we have been considering is whether evidence of prejudice and discrimination can tip the scale against an end when there are valuable alternatives that are less risky.

IV. The Moral Argument for Optimism

If one accepts the arguments of the previous section, then pragmatic reasons to resist pessimism traps are unpersuasive in these cases because forgoing more modest, but valuable, ends is a risky endeavor that can come with hefty opportunity costs. However, one might argue that Julio, Malcolm, and Clara have moral reasons to either pursue the ambitious ends in situations like this despite the opportunity costs. Alternatively, one might argue that they have moral reasons to resist forming the pessimistic beliefs supported by the evidence. In this section, I consider these arguments in turn.

\section{Moral Obligation}

When agents fall prey to pessimism traps they not only fail to provide evidence to their future self of their success at achieving the ambitious end in question, they also potentially reinforce the evidential basis that might lead other agents in a similar position to the pessimistic conclusion. Let's take the case of Clara. Should she to decide to pursue philosophy and succeed, she would change the evidential situation for future young Latina philosophy students considering pursuing an academic career in philosophy. One might argue that by failing to pursue the ambitious end, Clara is not being responsive to a moral obligation she has to change the evidential situation for future Claras. Were she to be optimistic despite the evidence, then she would make it more likely that she would succeed and thus she would make the evidential situation better for those who would follow in her wake. Though it is admirable that some agents decide to pursue ambitious ends of this sort for moral reasons despite the risks involved, the argument that doing so is morally required is weak. However, it is instructive to consider why this argument fails.

The first reason is that Clara's pursuit of philosophy is unlikely to dramatically change the evidence for future Latina philosophy students. If she succeeds, she makes the evidence very slightly better for future Claras. And if she fails, she makes the evidence for future Claras slightly worse. This is a version of the 'inefficacy problem' that arises in contexts of collective harm (Nefsky 2019). So even if we think that there is a potential harm to future Claras from the lack of Latina philosophers in the academy, it is unlikely that Clara would have much causal influence on changing that situation. Second, it is unclear whether there is a potential harm that Clara is responsible for mitigating here. Historically, the reasons that have led to the marginalization of Latinx, Blacks, women, and other minorities from philosophy are not that people from those groups failed to pursue philosophy. Until very recently, women and racial minorities were systemically excluded from paths into the academy. ${ }^{18}$ Therefore, unlike other cases of collective harm such as climate change, it is not obvious that the collective responsibility for remediation is on people like Clara. This leads to the third reason why this argument is unpersuasive: even if Clara had a reason to pursue philosophy in order to make it easier for the next generation of Claras, it's not clear

\footnotetext{
${ }^{18}$ The same can be said about working-class people's access to university (Julio's case) and African American's access to the legal profession (Malcolm's case).
} 
that this would be the kind of reason that would outweigh the potential harms that she would suffer were she to fail. She is in a 'double-bind' but not one that in which the options are equally harmful to her (Hirji Forthcoming).

The reason that I think this 'collective moral obligation' argument might seem prima facie appealing despite its clear shortcomings is that part of the solution to the evidential situation faced by these agents would seem to require collective action. If what members of marginalized groups need is evidence that people like them succeed in the pursuit of difficult, long-term goals from which they have been historically marginalized, how are they going to get that evidence if members of that group do not pursue those ends? We need pathbreakers, yet haven't I argued that pathbreaking is irrational? Before I proceed to respond to this concern, I should note that I have not argued that pathbreaking is irrational in all cases. It is only irrational according to the argument developed in this paper when an agent doesn't have an abnormally high tolerance for risk, doesn't value $\mathrm{E}_{\mathrm{A}}$ so much more than any other valuable alternative, or doesn't have strong evidence that they themselves are extraordinary. In some cases, agents might have evidence that defeats or undercuts the statistical evidence that members of their group tend to not succeed at the pursuit of $\mathrm{E}_{\mathrm{A}}$. An extraordinary athlete who sees that he is faster than anybody he has ever ran against might have evidence that he is the statistical anomaly. But if pursuing engineering, law, or philosophy requires such evidence, then this is no solution at all for most agents from marginalized groups. In the more quotidian cases, agents risk paying steep opportunity costs if they are not sensitive to evidence of potential failure in deciding what ends to adopt. To make the argument that agents in the position of Julio, Malcolm, and Clara are morally obligated to pursue the ambitious ends in question would require that we show that these agents are obligated to pay those steep opportunity costs.

\section{Doxastic Wronging}

Another way to resist pessimism traps could target the pessimistic beliefs as morally problematic themselves. One might argue that the agents in question are drawing problematic classist or racist beliefs about their own capacities; that is, they are engaged in a kind of doxastic wronging (Basu 2019a, 2019b, Basu and Schroeder 2019).

Doxastic wronging is a term that has been used to apply to the problematic racist and sexist beliefs that one agent can have of another even when the evidence would seem to otherwise license the belief. Rima Basu and Mark Schroder (2019) have argued that we can wrong someone not just by what we do, but what we believe about them. They suggest that even when the evidence might support a racist belief, moral reasons should shift the standards we use in forming such beliefs. They write "On our view, any belief is epistemically rational just in case it is supported by sufficient evidence. But the bar for sufficiency on evidence is sensitive to moral considerations" (p. 175). The bar for forming beliefs that take the form of generalizations about race and gender is set very high. So high, in fact, that most of our beliefs that include such social categories would be unjustified. Sarah Moss (2018) suggests that "in many situations where you are forming beliefs about a person, you morally should keep in mind the possibility that they might be an exception to the statistical generalization" (p. 190). To fail to do so, she suggests, might be a form of disrespect. The thought that there is something wrong with employing stereotypes in drawing conclusions about others is widespread, so perhaps we can rely on insights from that literature and apply it to the case in which agents are drawing on stereotypes to form beliefs about themselves. One might argue that in arriving at the belief that he is unlikely to succeed in pursuing the law, Malcolm is 
wronging himself either by using an incorrect evidential standard or by relying on group statistical evidence to draw conclusions about his own capacities.

Even if these views are persuasive in the case of classist and racist beliefs about others, they do not offer a persuasive analysis of the cases under consideration. And here we get to a key difference. Julio, Malcolm, and Clara could have high confidence and faith in their own abilities as potential engineers, lawyers, and philosophers and, nonetheless, draw the conclusion that the pursuit of each of those ends is too risky for people like them. After all, they might arrive at the quite reasonable belief that even those who are very capable are unlikely to succeed in those pursuits because of how members of their socioeconomic background, racial and gender groups have historically fared in the face of poverty, racism, and discrimination. Agents who see the challenges that poverty, race, and gender pose in their paths need not buy into problematic stereotypes about themselves; they only need to notice the way in which the world is structured to disadvantage members of those social groups. To do so they do have to accept certain generalizations such as that: employers are less likely to hire Black or Brown applicants; people who are born into poverty are very likely to stay in poverty; and so on. But these are not problematic generalizations - this is what we learn in the social sciences. ${ }^{19}$ A young Black man who walks into a White neighborhood and is nervous about being targeted by the police need not buy into any stereotypes about the danger he poses in virtue of his race; rather, he has the reasonable belief that others do operate using such stereotypes and that this poses a danger to him. If the picture that we have of doxastic wronging excludes such beliefs for failing to meet the bar for justification, then we have set the bar in the wrong place.

Part of the moral problem that one might have with generalizations about gender or race is that they easily seem to lead to the reification of categories that we would hope to do away with in an ideal world (Haslanger 2000). However, in the cases we have been considering the agents need not even be committed to existence of such categories to get the pessimistic belief off the ground. It is perfectively consistent to (a) believe that one is likely to be categorized as a member of group $\mathrm{G}$ (b) believe that people who are categorized as members of group $\mathrm{G}$ face greater obstacles in the achievement of $\mathrm{E}_{\mathrm{A}}$ and (c) believe that one is not a $\mathrm{G}$ or that there are no Gs. In other words, one need not even be committed to applying the generic to oneself (or to anyone else) in order to form the belief that the pursuit of $\mathrm{E}_{\mathrm{A}}$ is risky because one is classified by others as a member of G. Of course, I am not denying that there are cases similar to the ones we are considering in which agents do have problematic racist beliefs about themselves, but it is not a necessary feature of these cases that they do.

Hope

Let us turn now to hope-another potential contender in resisting pessimism traps. To be clear, what is at stake here is not simply whether we can rationalize the hope that poor people can overcome their disadvantage, that more African Americans become lawyers, or that more Latinas succeed in philosophy. In order for hope to license the agent pursuing $\mathrm{E}_{\mathrm{A}}$, hope would have to give Julio, Malcolm, and Clara sufficient reason to pursue a riskier end than they might have otherwise. ${ }^{20}$ However, as I will suggest, hope is best understood as a distinct attitude whose role is not to rationalize action when our beliefs fail to

\footnotetext{
${ }^{19}$ Some, like Beeghly $(2015,2018)$, argue that such generalizations are not morally problematic on other grounds.

${ }^{20}$ For a recent account that models hope as the kind of attitude that changes our willingness to take risks, see Rioux (Forthcoming). Though I find Rioux's account compelling, it too fails to adequately take into account opportunity costs that arise when there are less risky alternatives on offer.
} 
do so. Rather, hope enables an agent in a wide range of cases, particularly those in which the evidence is unfavorable, to focus on the possibility of success even when it is unlikely. Whether in such situations an agent should pursue an unlikely but valuable action depends not only on whether they hope for its success, but on the alternatives on offer and their likelihoods. Hope then is not a competitor for the beliefs we have been discussing, but rather a distinct attitude with a different functional role in the agent's moral psychology.

Consider, for example, Philip Pettit's (2004) view on which hope consists in acting on a belief that the agent does not have. He writes: "Hope will consist in acting as if a desired prospect is going to obtain or has a good chance of obtaining, just as precaution consists in acting as if this were the case with some feared prospect" (p. 158). But, as we have seen in our discussion, an agent who acts on the belief that she is likely to succeed in the face of evidence that does not support that claim risks paying significant opportunity costs. 'Acting as if' one has such a belief does not change the nature of the choice though it might enable the agent to sustain her pursuit even as the evidence mounts that she is unlikely to succeed. Now, in some cases, 'acting as if' is the right attitude to take. For example, Adrienne Martin (2016) in developing her account of hope considers the case of an agent who is given a dismal cancer diagnosis. She models hope as a practical attitude that leads this agent to treat her desire for the end as a practical reason to pursue it and the belief in its possibility as sufficient to license hopeful activities. For Martin, hope does not license ignoring the evidence but rather engaging in hopeful activities even when the possibility of the end coming about is very low. In the case of the cancer patient this is well-motivated as there are few opportunity costs to doing so and no salient valuable alternatives. However, it is hard to see how hope could justify 'acting as if' in the cases in which agents pay steep opportunity costs for doing so. ${ }^{21}$

This is not to deny that hope has a role to play in providing much needed comfort to those who are marginalized by their social class, race, or gender. Bovens (1999) suggests that a life with hope is better than a life without it, in part, because hope enables us to pursue goals that we might not otherwise. In some cases, an agent might value an ambitious end so highly that no matter how much more likely she is to succeed in pursuing an alternative, there is little value for her in anything but pursuing the ambitious end. In such cases, hope can be the sort of the attitude that sustains an agent's commitment to a goal. However, as Katie Stockdale (2019) argues, oppression can also threaten and damage an agent's capacity to hope. She argues that experiences of oppression can make it hard for agents to sustain the belief in the possibility of the hoped-for end and their desire to bring it about. Her argument helps us see the ways in which oppression can undermine both our beliefs in our capacities to bring about certain ends and our capacity to hope that they come about.

Nonetheless, there is a distinct role for hope to play here that distinguishes it from related beliefs concerning the likelihood of the agent's success. I suspect that many pathbreakers who saw overcoming the steep odds against them as extremely valuable were probably sustained in overcoming the challenges they encountered by hope. When the alternatives to the risky end are worse or the value of the risky end is very high, the agent might see no alternative but to hope.

\section{Epistemic Resilience}

${ }^{21}$ The argument here draws on the argument made in Morton and Paul (2019). 
Let us take stock of the argument thus far. Sociologists, economists, and psychologists seem to suggest that optimism can be a powerful way to get out of pessimism traps. However, justifying optimism in the face of evidence that one might fail turns out to be quite difficult. Agents who face obstacles that are the product of social class, race, or gender are in vulnerable positions. Pragmatic reasons to be optimistic could lead agents to pay steep opportunity costs. Moral reasons to be optimistic would seem to put the onus for rectifying injustice unjustly on the agents who are the victims of it. And yet, the pessimistic conclusion is a hard one to accept. Without optimism, agents in pessimism traps are stuck, unable to rationally opt for the ambitious end. Surely, in some cases, we can make the argument that optimism is warranted. What we need is a middle ground - a view that leaves room for optimism while allowing agents to be sensitive to evidence that the risks are too great.

In other work with Sarah Paul (2019) we have defended the view that grit involves a kind of epistemic resilience that sustains an agent's confidence in her capacity to pursue a difficult, long-term end $\mathrm{E}_{\mathrm{A}}$ in the face of challenges and setbacks that threaten her confidence. On our view, epistemic resilience is a rational form of optimism that allows us to sustain our commitment to an end, once we have settled on it, even as we face challenging circumstances and remain attuned to evidence of potential failure. However, the argument we offer does not address the question of whether an agent should be optimistic about her likelihood of success prior to settling on an end. Could we extend the view to license optimism in the cases we have been considering?

To understand how we might do so, we must begin by clarifying the theoretical underpinnings of the view. Evidentialism tells us that agents who are reasoning about whether to believe P should only take into account considerations that bear on the truth of whether P. However, as we suggest, evidence about whether one is likely to succeed at pursuing a difficult, long-term goal is rarely definitive. In many cases, the evidence points in multiple directions and reasonable impartial observers could disagree about what the evidence shows. We argue that even if agents are only responding to evidence that is truth-relevant when they deliberate about how likely they are to achieve P, in many cases there will be multiple epistemically permissible ways of responding to that evidence..$^{22}$ In some such cases, pragmatic reasons can favor an evidential policy that licenses the disposition to interpret evidence optimistically, but in a way that is compatible with evidentialism.

In our view, in cases in which an agent has settled on an end, a gritty evidential policy sets a higher threshold for how weighty the evidence must be in order for the agent to conclude that she is unlikely to succeed and, thus, abandon her end. ${ }^{23}$ This is a very moderate form of pragmatic encroachment that doesn't permit an agent to use pragmatic or moral reasons at the $1^{\text {st }}$-order level but does allow that such considerations can play a role in lending support to how an agent is disposed to respond to evidence. This allows the agent to have a disposition that prevents her from giving up on her goals too quickly, while allowing her to retain sensitivity to evidence of potential failure. This allows us to distinguish epistemic resilience, which is constrained to the evidential threshold of reasonable agreement compatible with evidentialism, from hope, which only requires that the agent desire the end in question and believe it to be possible.

\footnotetext{
22 The argument depends on a moderate and limited form of permissivism that I do not have the space to defend here. For a discussion of permissivism, see Schoenfield (2014).

${ }^{23}$ This model is similar to that used by Basu and Schroeder (2019) to model their argument for moral encroachment.
} 
I now want to suggest that we can extend the epistemic resilience model to the cases we are considering. When an agent is faced with the prospects of whether to pursue $E_{A}$ or $E_{M}$ and the evidence is such that two disinterested observers could reasonably disagree about whether the agent's likelihood of success is high in the pursuit of the ricker end, an agent with an optimistic evidential policy would be justified in responding to the evidence in a way that sides with the positive interpretation of her likelihood of success. Note that in such cases both the optimistic and the pessimistic interpretation of the evidence are justified by the first-order evidence. Therefore, this view is compatible with evidentialism at the firstorder level.

This view allows us to understand a crucial potential difference between Malcolm and Clara. The evidence that Malcolm has is quite compelling in supporting the view that it is unlikely that he would be able to overcome all the challenges on his path to becoming an attorney. That is, it is unlikely that this case falls within the range of reasonable disagreement. Epistemically rational agents would agree that this end is extremely risky. However, one might argue that Clara's case is not of this sort. Reasonable people could disagree about whether she is likely to succeed in philosophy. And if we fill in the details so as to construe the evidential situation in this way, then it might be reasonable and epistemically rational for Clara to be the sort of agent who has an optimistic evidential policy that allows her to look at the evidence in front of her more favorably. But note that this dispositions to look at the evidence optimistically wouldn't extend to cases in which it is clear that the evidence points to a pessimistic assessment.

This model of epistemic resilience can allow us to distinguish reasonable from unreasonable appeals to optimism. Return to Julio's case. Should he be optimistic about his likelihood of succeeding at pursuing higher education in the capital? If he has an evidential policy that supports optimism in the way described above, then it would only license optimism if evidence of his likelihood of success falls within the threshold of reasonable disagreement. The case, as described, does not offer much evidence that he would succeed. But we might fill in the details in such a way that it becomes more reasonable for him to think so. Perhaps Julio wins a scholarship that would pay for his living expenses and he has a teacher who has attended that university and has assured him she will offer him guidance throughout his undergraduate trajectory. Note, however, that this sort of evidence would not only bring Julio closer to the threshold of reasonable disagreement that would license optimism, it would also materially change the riskiness of the pursuit.

Those who decry the appeal to optimism by economists like Esther Duflo and psychologists like Angela Duckworth are right that in many situations the evidence agents face under conditions of oppression cannot support optimistic beliefs because the conditions are not such that one can reasonably expect to succeed. As I have argued, to require that agents believe against the evidence is unreasonable when agents who are already marginalized risk having to pay high opportunity costs in the pursuit of risky ends. But this does not mean that there is no role for optimism to play here. In cases in which the evidence falls within the realm of reasonable disagreement, one might argue that being optimistic about what the evidence does show is an important capacity that agents need in order to successfully commit to difficult, long-term ends and succeed in their pursuit in the face of challenges and setbacks, even when these include poverty, discrimination, and prejudice. ${ }^{24}$ This view offers a moderate reframing of how

\footnotetext{
24 This capacity is necessary, but not sufficient. There might be other ways in which poverty affects decision making that are relevant to consider, see Mullainathan and Shafir (2013) and Morton (2017).
} 
agents in such situations should form optimistic beliefs, while remaining attentive to evidence that the risk is not worth the opportunity costs. ${ }^{25}$

\section{Collective Responses to Pessimism Traps}

The epistemic resilience approach to pessimism traps is limited. It only licenses agents to be optimistic when cases fall within the threshold of reasonable disagreement. This means that Malcolm and Julio, even if they adopted the kind of optimistic evidential policy licensed by this account, would not be licensed in being optimistic about their likelihood of success in pursuing the ambitious ends in question. What the argument advanced in this paper shows us is that our beliefs about what we are able to achieve depends on what others around us in similar positions also achieve. This insight is well-supported by research that shows that people from groups that have been historically subject to discrimination and prejudice do tend to be sensitive to evidence of how successful people who are similarly situated to them are in pursuing certain ends. A recent study on innovation by Alex Bell, Raj Chetty, and collaborators (2018) shows, perhaps unsurprisingly, that "exposure to innovation during childhood has significant causal effects on children's propensities to invent" (p.647). What is more surprising is that "Girls are more likely to invent in a particular class if they grow up in an area with more women (but not men) who invent in that class" (p. 647-8). Their research suggests that role models and network effects are powerful mediators in the career paths that people endeavor to pursue, but that women and minorities are particularly sensitive to evidence of members of their own group pursuing such paths. If the argument I have defended in this paper is right, then these agents are behaving rationally by being sensitive to such evidence in deciding whether to pursue risky careers as inventors. The problem is that this mechanism would seem to further entrench the situation of those who face such pessimism traps.

One potential overlooked response, hinted at in section IV, is to reconceive of pessimism traps as a challenge that is best dealt with by collectives rather than individuals. If the evidence we need is evidence at the level of a group, then perhaps what we need is group action. ${ }^{26}$ Successful movements that have advanced the interest of the poor, racial minorities, and women have largely been the product of collective action. We see this strategy at play in programs geared towards diversifying the philosophy profession that focus on bringing members of minority groups together. And in the success of programs that target first-generation student retention by putting students into cohort groups (Tinto 2010). By overcoming these barriers as a group, agents are not only bolstered by solidarity with others but, interestingly, provide each other with evidence of their joint success. The individual's assessment of her success is now not only dependent on her own effort, but on the collective effort of her group. This might give rise to a kind of optimism whose basis extends far beyond evidence about how likely $I$ am to succeed but how likely we

\footnotetext{
${ }^{25}$ It is important to note that we justify our view pragmatically. That is, we suggest that this is a good policy to adopt because it leads agents to do better than they would if they were to employ a policy that would lead them to quit difficult-long term goals whenever they encountered setbacks and challenges. But it is an open question whether agents who face poverty, prejudice, and discrimination do better adopting such a policy-it depends on how things turn out. Agents who are optimistic, but due to such conditions, keep failing and thus paying high opportunity costs have reason to adopt a less optimistic evidential policy. Being extremely sensitive to evidence of potential setbacks and challenges that arise from prejudice and discrimination might be a way for such agents to protect themselves from taking on risks that might be very costly. In such cases, epistemic resilience stops being pragmatically justified. We allude to this argument in Morton and Paul (2019)

${ }^{26}$ Another consideration in support of this contention is that the choices we even consider seems to be influenced by the social norms that are prevalent in our environment. For a discussion of this see Muldoon (2017).
} 
are to succeed. This is not the place to explore this notion, but it is a critical one to consider in further work that contends seriously with pessimism traps.

\section{Conclusion}

I have argued that evidence of barriers such as poverty, prejudice, and discrimination can quite reasonably lead agents to see the pursuit of a difficult, long-term, ambitious end $\mathrm{E}_{\mathrm{A}}$ as risky. When those agents have less risky, valuable alternatives $E_{M}$ it is rational for them to opt for those modest alternatives. I have argued against one promising way of resisting this argument—believing against the evidence — and suggested that this is a dangerous and potentially very costly strategy for agents in vulnerable positions. I have also suggested that the moral argument in favor of agents pursuing these ambitious ends at great cost to themselves is unpersuasive. The view that can help us model a kind of optimism that doesn't fall prey to these worries - the epistemic resilience account - is limited in scope to those cases in which the evidence falls within the threshold of reasonable disagreement.

The largely negative view advanced in this paper echoes that of defenders of pessimism in feminist and African American philosophy. Kathryn Norlock (2019) argues that we are better off rejecting the hopeful promise of progressivism in favor of a pessimism that draws tools from stoicism to allows us to enjoy those goods that are achievable in an unjust world. Derrick Bell (1991) suggest that we should accept that, "Black people will never gain full equality in this country. Even those herculean efforts we hail as successful will produce no more than temporary 'peaks of progress,' short-lived victories that slide into irrelevance as racial patterns adapt in ways that maintain white dominance" (p. 373). Both Norlock's and Bell's critiques cut much deeper than the one advanced here. They are skeptical that structures of disadvantaged can be overcome at all. The view I defend doesn't preclude the possibility that there might be effective collective approaches to pessimism traps. My argument only aims to show the limitations we face in overcoming pessimism traps as individuals who are liable to pay the opportunity costs that come from failure.

More practically, the argument of this paper also suggests that policy interventions are often insufficiently attentive to the evidential dimension of disadvantage. Simply being encouraged to believe that one can attend college or that scholarships are available might not be enough to counteract the negative evidence that abounds in environments with concentrated disadvantage. Concentrated disadvantage itself, according to this view, might be unjust not only because of the material deprivations it imposes on agents, but because it provides them with little evidence that could support the sort of optimistic beliefs that are central to ambition. The anthropologist Arjun Appadurai (2013) has argued that the poor are often deprived of the capacity to aspire because they have fewer models around them that link means to ends, that is, of examples of those who have successfully pursued a broad range of ambitious ends. I would not go as far as Appadurai in categorizing the situation of the poor as a deficit of aspiration; agents can aspire to be good parents, kind to their neighbors, or sources of comfort in their community. But the argument of this paper does lend support to the importance of evidence in considering whether a particular context is supportive (or not) of the kind of optimism that fuels the sort of aspirations that we are expecting those in conditions of adversity to adopt. 


\section{References}

1. Appadurai, A. (2013). The Capacity to Aspire: Culture and the Terms of Recognition. In The Future as Cultural Fact: Essays on the Global Condition (179-196), London: Verso Books.

2. Aronson, J., C. B. Fried, et al. (2002). Reducing the effects of stereotype threat on African American college students by shaping theories of intelligence. Journal of experimental social psychology, 38 (2), 113-125.

3. Bandura, A. (1977). Self-efficacy: toward a unifying theory of behavioral change. Psychological review, 84(2), 191-215.

4. Banerjee, A. V. and E. Duflo (2011). Poor economics: A radical rethinking of the way to fight global poverty, New York: Public Affairs.

5. Basu, R. (2019a). The Wrongs of Racist Beliefs. Philosophical Studies, 176(9), 2497-2515.

6. Basu, R. (2019b). Radical Moral Encroachment: The Moral Stakes of Racist Beliefs, Philosophical Issues, 29 (1), 9-23.

7. Basu, R. and Schroeder, M. (2019). Doxastic Wronging, In B. Kim and M. McGrath (Eds.), Pragmatic Encroachment in Epistemology, New York: Routledge, 158-178.

8. Beeghly, E. (2015). What is a stereotype? What is stereotyping? Hypatia, 30 (4), 675-691,

9. Beeghly, E. (2018). Failing to Treat Persons as Individuals. Ergo, 5 (26), 687-711. Doi: https://doi.org/10.3998/ergo.12405314.0005.026

10. Bell, A., R. Chetty, et al. (2018). Who Becomes an Inventor in America? The Importance of Exposure to Innovation. The Quarterly Journal of Economics, 134 (2), 647-713.

11. Bell, D. (1991). Racial realism. Connecticut Law Review, 24 (2), 373-379.

12. Bovens, L. (1999). The value of hope. Philosophy and Phenomenological Research, 59 (3), $667-$ 681.

13. Bovens, L. (1999). The value of hope. Philosophy and Phenomenological Research, 59(3), 667681.

14. Bratman, M. (1984). Two Faces of Intention, The Philosophical Review, 93(3): 375-405.

15. Bratman, M. E. (2000). Valuing and the Will (Volume 14: Action and Freedom), Nous Supplement: Philosophical Perspectives, 14, 249-265.

16. Bratman, M. E. (2004a). Shared Valuing and Frameworks for Practical Reasoning, in Reason and Value: Themes from the Moral Philosophy of Joseph Raz. R. J. Wallace, S. Scheffler and M. Smith. Oxford: Clarendon Press, 1-28.

17. Bratman, M. E. (2004b). Three Forms of Agential Commitment: Reply to Cullity and Gerrans, Proceedings of the Aristotelian Society, 104, 329-337.

18. Britner, S. L. and F. Pajares (2001). Self-efficacy beliefs, motivation, race, and gender in middle school science. Journal of Women and Minorities in Science and Engineering, 7 (4), 269-83.

19. Buchak, L. (2013). Risk and Rationality, Oxford: Oxford University Press.

20. Cohen, G. L., J. Garcia, et al. (2006). Reducing the racial achievement gap: A socialpsychological intervention. Science 313 (5791), 1307-1310.

21. Cohen, G. L., J. Garcia, et al. (2009). Recursive processes in self-affirmation: Intervening to close the minority achievement gap. Science, 324 (5925), 400-403.

22. Duckworth, A. (2016). Grit: The power of passion and perseverance. New York: Simon and Schuster.

23. Duflo, E. (2012). Human Values and the Design of the Fight Against Poverty. Tanner Lectures. Harvard University, 
https://www.povertyactionlab.org/sites/default/files/documents/TannerLectures_EstherDuflo_draf t.pdf.

24. Haslanger, S. (2000). Gender and race: (What) are they? (What) do we want them to be? Noûs, 34 (1), 31-55.

25. Hieronymi, P. (2009). Believing at will. Canadian Journal of Philosophy, 39, 149-187.

26. Hirji, S., (Forthcoming). Oppressive Double Binds. Ethics.

27. Lippert-Rasmussen, K. (2011). 'We are all Different': Statistical Discrimination and the Right to be Treated as an Individual. The Journal of ethics, 15(1-2), 47-59.

28. Malcolm, X. (2015). The autobiography of Malcolm X, New York: Ballantine Books.

29. Martin, A. (2016). How We Hope: A Moral Psychology, Princeton: Princeton University Press.

30. Marušić, B. (2015). Evidence and Agency: Norms of Belieffor Promising and Resolving, New York: Oxford University Press.

31. Morton, J. M. (2017). Reasoning Under Scarcity. Australasian Journal of Philosophy, 95 (3), 543-559.

32. Morton, J. M., \& Paul, S. K. (2019). Grit. Ethics, 129 (2), 175-203.

33. Moss, S. (2018). IX-Moral Encroachment. Proceedings of the Aristotelian Society, 118 (2), 177 205.

34. Muldoon, R. (2017). Perspectives, Norms, and Agency. Social Philosophy \& Policy, 34 (1), $260-$ 76.

35. Muldoon, R. (2017). Perspectives, Norms, and Agency. Social Philosophy \& Policy 34(1): 260.

36. Mullainathan, S. and E. Shafir (2013). Scarcity: Why Having Too Little Means So Much. New York: Times Books

37. Nefsky, J. (2019). Collective harm and the inefficacy problem. Philosophy Compass, 14 (4), doi: https://doi.org/10.1111/phc3.12587

38. Norlock, K. J. (2019). Perpetual Struggle. Hypatia, 34 (1), 6-19.

39. Paul, S. K. (2021). Plan B. Australasian Journal of Philosophy. Advance online publication. Doi: https://doi.org/10.1080/00048402.2021.1912126

40. Pettit, P. (2004). Hope and its Place in Mind. The Annals of the American Academy of Political and Social Science, 592 (1), 152-165.

41. Preston-Roedder, R. (2018). Three Varieties of Faith, Philosophical Topics, 46 (1), 173-199

42. Rioux, Catherine (Forthcoming). Hope as a Source of Grit, Ergo.

43. Schoenfield, M. (2014). Permission to believe: Why permissivism is true and what it tells us about irrelevant influences on belief. Noûs, 48(2), 193-218.

44. Seligman, M. E. (2006). Learned optimism: How to change your mind and your life. New York: Vintage.

45. Setiya, K. (2008). Believing at will. Midwest Studies in Philosophy, 32 (1), 36-52.

46. Steele, C. M. and J. Aronson (1995). Stereotype threat and the intellectual test performance of African Americans. Journal of personality and social psychology 69 (5), 797-811.

47. Stockdale, K. (2019). Social and Political Dimensions of Hope. Journal of Social Philosophy, 50 (1), 28-44.

48. Stroud, S. (2006). Epistemic Partiality in Friendship, Ethics, 116 (3), 498-524.

49. Tenney, Elizabeth R., Jennifer M. Logg, and Don A. Moore (2015). (Too) optimistic about optimism: The belief that optimism improves performance. Journal of personality and social psychology, 108 (3), 377-399. 
50. Tinto, Vincent (2010). From Theory to Action: Exploring the Institutional Conditions for Student Retention. In Smart, J. (Ed.), Higher education: Handbook of Theory and Research Vol. XXV (pp. 51-89). New York: Springer, Dordrecht.

51. Winters, B. (1979). Believing at will. The Journal of Philosophy, 76 (5), 243-256.

52. Worsnip, A. (2020). Can Pragmatists Be Moderate? Philosophical and Phenomenological Research, Advanced online publication. doi: https://doi.org/10.1111/phpr.12673 